\title{
Experimental Study of Coal Sample Damage in Acidic Water Environments
}

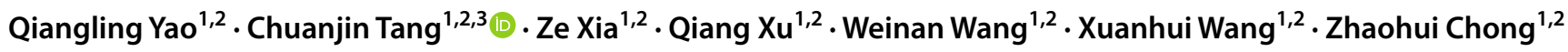

Received: 7 October 2020 / Accepted: 27 July 2021 / Published online: 12 August 2021

(c) Crown 2021

\begin{abstract}
We investigated the effects of acidic and circumneutral water on coal samples by uniaxial compression, acoustic emission, and a series of physical tests. In acidic water, the coal samples were damaged, and their ultrasonic velocities decreased, as minerals such as kaolinite and calcite underwent dissolution. When the $\mathrm{pH}$ was $<7$, the uniaxial compressive strength and elastic modulus decreased, while the duration of the residual strength stage tended to increase. The reactions were stronger at higher $\mathrm{H}^{+}$concentrations and the number of large pores increased; there was a significant increase in the accumulated acoustic emission counts and maximum average energy near the unstable crack growth stage. The post-peak stage of the coal samples was characterized in the different acidic waters and the failure modes were identified by spectrum analysis. Acidic water damaged the weak areas of coal samples by complex physical and chemical reactions, which made direct tensile failure more likely when the coal samples were loaded.
\end{abstract}

Keywords Underground water reservoir $\cdot$ Hydrochemistry $\cdot$ Coal microstructure $\cdot$ Mechanical property $\cdot$ Crack evolution · Acoustic emission

\section{Introduction}

Since 2000, coal has continued to account for more than $65 \%$ of China's energy. There are 14 large coal bases in China, namely in Shendong, Shaanbei, Huanglong, Jinbei, Jinzhong, Jindong, Luxi, Lianghuai, Jizhong, Henan, Yungui, Mengdong (northeast), Ningdong, and Xinjiang. Among them, 10 are located in arid and semi-arid areas in western China, making this the strategic focus of coal production in China. However, these areas contain less than $7 \%$ of the country's total water resources, and evaporation exceeds precipitation. Therefore, this region is generally coal-rich and water-deficient. Coal production can consume a huge amount of water and destroy overburden aquifers. This loss

Chuanjin Tang

chuanjin.tang@nottingham.ac.uk

1 Key Laboratory of Deep Coal Resource Mining, Ministry of Education of China, China University of Mining and Technology, Xuzhou 221116, China

2 School of Mines, China University of Mining and Technology, Xuzhou 221116, China

3 Department of Civil Engineering, University of Nottingham, Nottingham NG7 2RD, UK of groundwater accelerates surface plant degradation and desertification. As a consequence, a vicious circle (less water resources, less coal production, and poor ecological environment) is formed, which severely restricts coal production, living standards, and the ecological environment (Song et al. 2020; Sun et al. 2020; Yang et al. 2019b).

The coal seams in western China are relatively near the surface and the roof fractures can easily extend directly to the surface (Fig. 1). Fractures in the overburden strata are affected by the mining disturbance and extend upward to the aquifers, forming water-flowing fractured zones that provide transfer channels for groundwater (Liu et al. 2019b; Miao et al. 2011). Traditional water conservation mining methods involve controlling the developmental height of the fractured zones below the aquifers, and include strip mining, backfill mining, room and pillar mining, and restricted height mining (Chang et al. 2014; Fan et al. 2019; Huang 2017; Zhu et al. 2018). Mine water is generally discharged to the surface for treatment, resulting in wastewater and pollution $(\mathrm{Li}$ et al. 2017; Wang et al. 2016). Using these methods, it is difficult to simultaneously achieve high coal production, groundwater protection, and low cost.

This study was motivated by an underground water reservoir construction project and was conducted in cooperation 


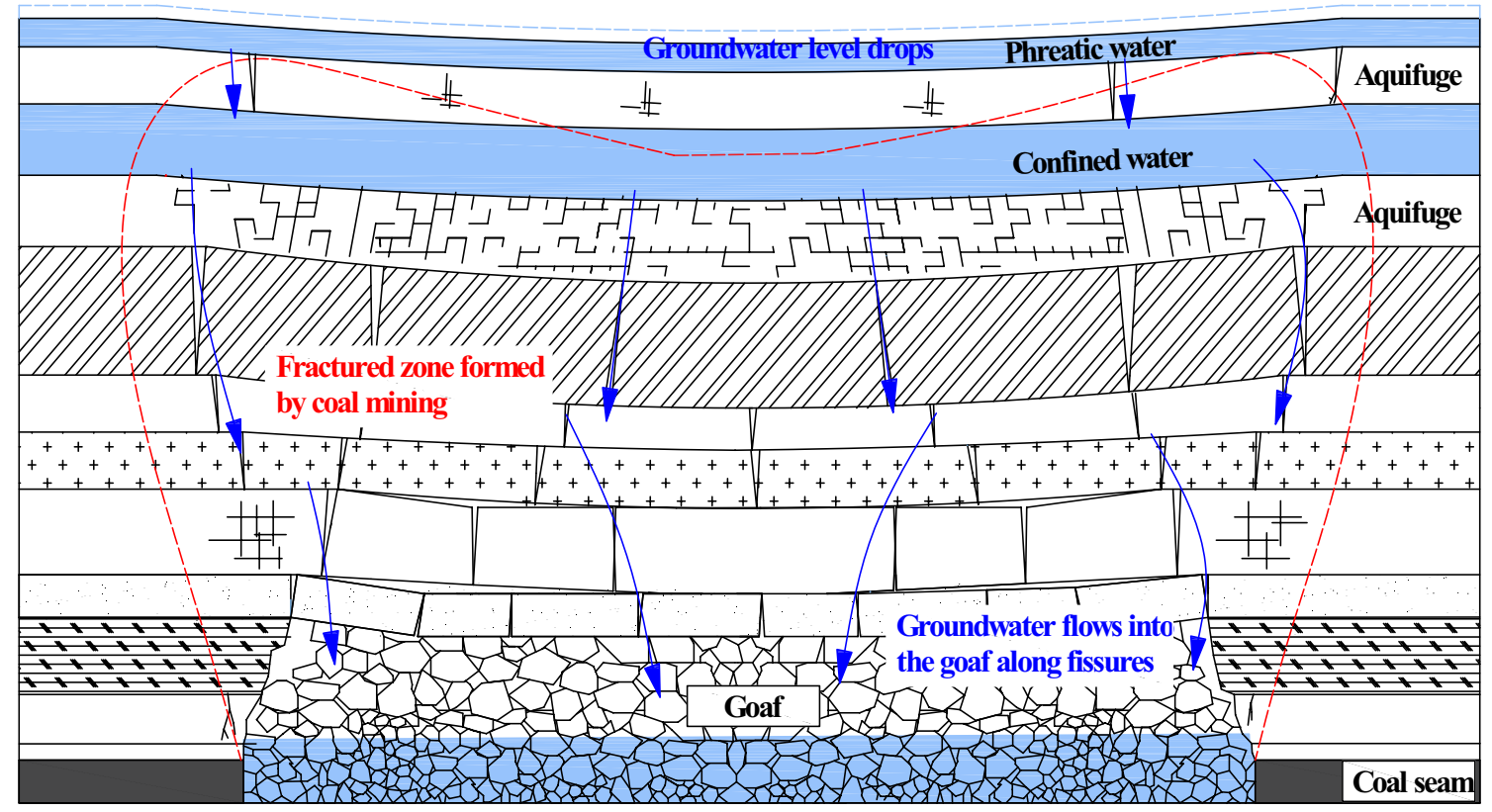

Fig. 1 Schematic diagram of the water flowing fractured zone above a shallowly buried coal seam

with a coal mining enterprise. The construction involved connecting the coal pillars of the goaf with artificial dams and making full use of the unoccupied goaf space to store water (Gu 2015; Tang et al. 2019). The objective was to collect the flowing water (from aquifers and underground water, wastewater, etc.) generated by coal mine activities into an underground water reservoir to take advantage of the natural adsorption capacity of the gangue in the goaf to reduce the concentration of total dissolved solids in the mine water. The mine water will then be further treated (purified) according to its intended use.

Good stability of coal pillar dams is essential for longterm use of such groundwater reservoirs (Wang et al. 2019c). Coal is a discontinuous and heterogeneous multiphase complex engineering rock mass that often contains associated minerals and irregular pores and fractures. When there is pyrite nearby or the coal seams have a high sulfur content, the mine water is prone to be acidic due to chemical and microbial action (Galhardi and Bonotto 2016; Madzivire et al. 2014). In acidic water environments, coal pillar dams undergo complex physical and chemical reactions that can change their bearing structure and stability.

Water penetrates into mineral particles, cements, and structural surfaces, thus leading to lubrication, softening, dissolution, and structural changes in the structure and stress state of the rock mass (Wang et al. 2019b; Zhou et al. 2018). The influence of the water is largely related to the rock's porosity and the proportion of certain minerals, especially quartz and expanded clay minerals (Cai et al. 2019). Cation exchange can change the attractive and repulsive forces between particles and clay mineral hydration can cause uneven stress (Wang et al. 2020b). Pores with poor connectivity under stress have high pore water pressure and tensile failure. For soft coal, as the water saturation increases, the uniaxial compressive strength first increases and then decreases (Gu et al. 2019). For ordinary rocks and hard coal, water generally only leads to strength reduction (Feng et al. 2019; Qian et al. 2019) because the water-rock interaction reduces rock cohesion (Guo et al. 2018; Li et al. 2019), degrades fracture toughness, and promotes subcritical crack propagation (Hao et al. 2015; Ma et al. 2018).

Water-rock interaction also promotes the redistribution of different chemical elements and isotopes between the rock mass and water through dissolution, adsorption, isotope exchange, redox reactions, and percolation differentiation, and is an important aspect of element migration (Corteel et al. 2005; Ding 1989). Acidic solutions seriously damage natural rocks: the number of pores increases, the pore sizes increase, the carbonate minerals content decreases, and the concentration of leached ions increases (Lin et al. 2019; Ma et al. 2019). In addition to directly soaking the rock samples in a specific solution to study the chemical interaction between water and rock, researchers have also used leaching or flow tests to explore such chemical interactions in flowing water. Wang et al. (2019a) studied brown coal and its salt sensitivity under constant effective stress by using water with different $\mathrm{pH}$ and salinity values as injection liquid, and found that the wettability, water film thickness, and the $\mathrm{pH}$ were the key factors. Through leaching experiments, Yu et al. (2015) found that the microelement concentrations in 
the leaching solution was controlled by the chemical properties of minerals in the rocks and the chemical environment and was also affected by the size of the particles and the time of action.

The use of underground water reservoir technology in coal mines has great potential but the long-term effect that the mine water might have on the coal pillar dams had to be studied. We investigated the properties of coal in acidic and circumneutral $\mathrm{pH}$ water and used ultrasonic wave speed, scanning electron microscopy (SEM), and $\mathrm{x}$-ray fluorescence (XRF) to explore the effect of $\mathrm{H}^{+}$on the composition and microstructure of coal samples. Furthermore, uniaxial compression and acoustic emission tests were used to investigate the potential effects that the water might have on the strength and fractures of the coal.

\section{Materials and Methods}

Coal was collected from operating face 31,313 of the Chahasu coal mine in northern China, sealed with plastic wrap, and transported to a plant where it was then processed into $50 \mathrm{~mm} \times 50 \mathrm{~mm} \times 100 \mathrm{~mm}$ cuboidal samples. The height direction was parallel to the layering direction. After excluding samples that had been damaged during the processing, drying, soaking, and transfer, 12 complete coal samples were selected for testing. Twelve plastic containers that could hold acidic solutions were used as the soaking containers. The solute was high-purity hydrochloric acid $(\mathrm{HCl})$ and the solvent was distilled water ( $\mathrm{pH} 7.3)$. We used $\mathrm{HCl}$ in our engineering project because the site's mine water did not necessarily have more sulfate ions than chloride ions and because it was easier for us to obtain concentrated $\mathrm{HCl}$ than concentrated sulfuric acid, although both are regulated and difficult to obtain.

The samples were divided into four groups with three samples in each group (the corresponding sample numbers are A1-A3, B1-B3, C1-C3, and D1-D3). The samples in groups $\mathrm{A}, \mathrm{B}, \mathrm{C}$, and $\mathrm{D}$ were soaked in $1000 \mathrm{ml}$ of acidic or neutral solution with a $\mathrm{pH}$ of $2,4,6$, and 7.3 , respectively for saturation (the solution acidity was measured by a PHS$3 \mathrm{C} \mathrm{pH}$ meter with an accuracy of $0.01 \mathrm{pH}$ ). The last three correspond to the $\mathrm{pH}$ of many mine waters, while the $\mathrm{pH} 2$ group represents an extreme case. Group D was a control group (distilled water). Referring to Ma et al. (2019) and Yao et al. (2019), the soaking time was set at $24 \mathrm{~h}$. To prevent the samples from disintegrating after being soaked, the saturated samples were sealed with plastic wrap and placed in a cool place in the laboratory for 60 days.

The ultrasonic velocity, microstructure, and elemental composition of the coal samples were measured before the mechanical and acoustic emission experiments. Uniaxial compression tests were performed using an electro-hydraulic servo universal testing machine (C64.106 type, MTS Industrial Systems (China) Co., Ltd., China) at a loading rate of $0.4 \mathrm{~mm} / \mathrm{min}$. The maximum test force of the machine is 1000 $\mathrm{kN}$ and the measurement accuracy is $\pm 0.5 \%$. An acoustic emission system (PCI-2 type, Physical Acoustic Corporation, USA) was used to collect acoustic emission signals in the loading process. The acquisition threshold was $40 \mathrm{~dB}$, the gain was $40 \mathrm{~dB}$, and the sampling frequency was $2 \mathrm{MHz}$. The main test system is presented in Fig. 2.

\section{Results}

\section{The Effects of the Coal on the Water}

The $\mathrm{pH}$ of the soaking solutions after the samples were saturated is listed in Table 1. In Group A, the $\mathrm{H}^{+}$concentration decreased by less than an order of magnitude, whereas the quantity of $\mathrm{H}^{+}$decreased the most. In groups $\mathrm{B}$ and $\mathrm{C}$, the $\mathrm{H}^{+}$concentration decreased by about two orders of magnitude, and the solutions were nearly neutral. The $\mathrm{H}^{+}$concentration of Group D (the control group) remained almost unchanged. These results reflect that higher $\mathrm{H}^{+}$concentrations promote chemical interactions between the water and minerals.

\section{Physical Characteristics of Coal Samples in Acidic Water}

\section{Ultrasonic velocity}

The ultrasonic velocity of the samples is shown in Fig. 3. The ultrasonic velocity of the dry samples ranged from 1.333 to $1.667 \mathrm{~km} / \mathrm{s}$, which suggests that the samples were fairly uniform. After the samples were saturated in acidic solutions and left for 60 days, the ultrasonic velocity generally decreased, dropping by $0.031-0.218 \mathrm{~km} / \mathrm{s}$. The internal structure and defect distribution of the samples changed after full water-coal physical and chemical interactions, manifesting a certain degree of damage. The ultrasonic velocity of samples A1, A2, and C3 rose slightly, possibly because

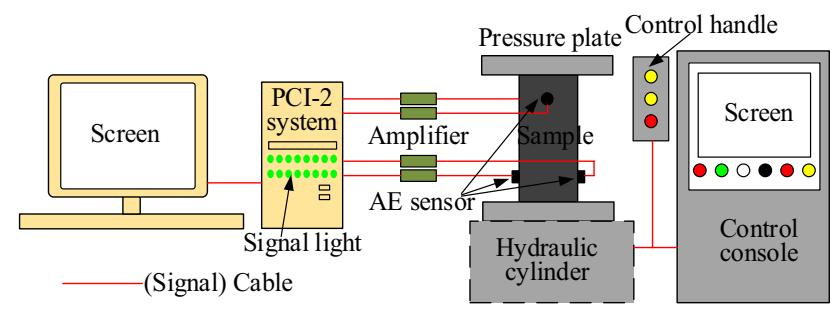

Fig. 2 Acoustic emission system (left) and electro-hydraulic servo universal testing system (right) 
Table 1 The $\mathrm{pH}$ of solutions before and after sample soaking

\begin{tabular}{lllll}
\hline & Group A & Group B & Group C & Group D \\
\hline pH before soaking & 2 & 4 & 6 & 7.3 \\
$\mathrm{H}^{+}$concentration before soaking/mol/L & $1.00 \times 10^{-2}$ & $1.00 \times 10^{-4}$ & $1.00 \times 10^{-6}$ & $5.00 \times 10^{-8}$ \\
$\mathrm{pH}$ after soaking & 2.08 & 6.63 & 7.81 & 7.44 \\
$\mathrm{H}^{+}$concentration after soaking/mol/L & $8.32 \times 10^{-3}$ & $2.34 \times 10^{-7}$ & $1.55 \times 10^{-8}$ & $3.63 \times 10^{-8}$ \\
\hline
\end{tabular}

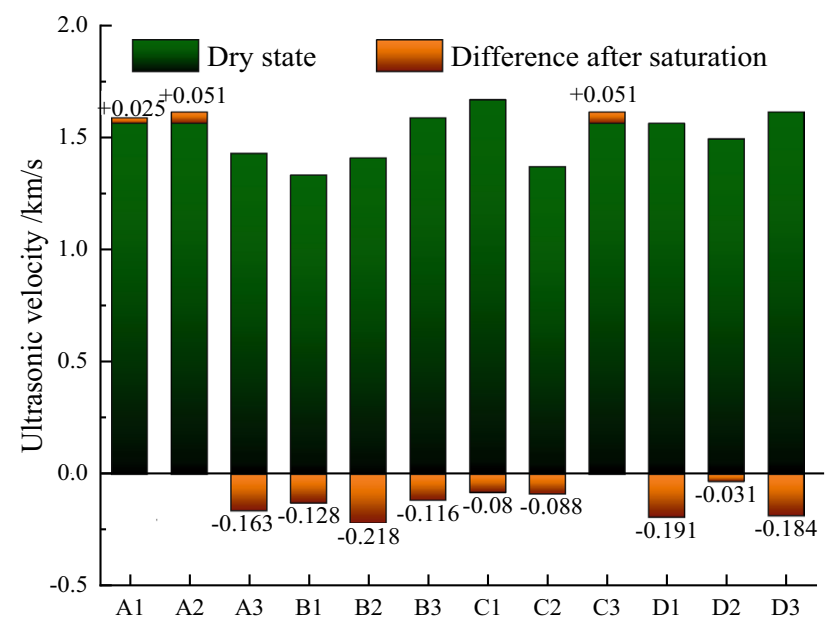

Fig. 3 Changes in ultrasonic velocity of samples after soaked in different acidic solutions (Groups A, B, C, D means pH 2, 4, 6, 7.3, respectively)

the long-term water-coal interaction made the clay minerals expand and fill the cracks, which enhanced their uniformity and allowed the ultrasonic waves to pass smoothly.

\section{Microstructural Characteristics}

A Quanta 250 scanning electron microscope (Thermo Fisher Scientific, Waltham, MA, USA) was used to observe the microstructure of coal samples and the development of primary pores, as shown in Fig. 4, and the pore sizes of the four groups of coal samples are shown in Table 2. The magnifications were 800,1200 , and 5000x, and the corresponding observation scales were 100,50 , and $20 \mu \mathrm{m}$, respectively. The surface microstructure of coal samples is complex, presenting fracture irregularity. There are more granular mineral crystals and more large dissolution pores (11 pores in observation areas with a diameter $>20 \mu \mathrm{m}$ ) on the surface in Group A. The maximum dissolution pore size in the veined structure of Group A was the largest at $\approx 27.3 \mu \mathrm{m}$. In Group B, there were groups of relatively large dissolution pores (e.g. of $\approx 24.1$ and $19.7 \mu \mathrm{m}$ ), but the number of pores with pore diameters above $15 \mu \mathrm{m}$ was less than in group $\mathrm{A}$, and the fracture surfaces were veined and irregular. In Group C, the maximum pore size was $15.9 \mu \mathrm{m}$ and there were groups of small dissolution pores, most $<15 \mu \mathrm{m}$. In
Group D, there were few primary pores, and the primary pores did not develop, with pore sizes $<5 \mu \mathrm{m}$. The acidic solutions dissolved the minerals in the microstructure of the coal samples. A comparison between several sets of results shows that the pore size increased and more debris particles appeared as the $\mathrm{pH}$ of the solutions decreased.

\section{Elemental Analysis}

The coal samples have the characteristics of low ash, low sulfur, ultra-low phosphorus, and high calorific value. The major element oxides (except carbon) in the coal samples account for less than $10 \%$ by mass and the mineral content is relatively small (Table 3 ). The main metal elements are $\mathrm{Ca}, \mathrm{Sr}, \mathrm{Al}, \mathrm{Fe}$, and the main nonmetallic elements are $\mathrm{Si}$, $\mathrm{S}$, and $\mathrm{P}$.

\section{Damage Evolution of the Coal Samples}

\section{Full Stress-Strain Curves}

Figure 5 presents the full stress-strain curves of coal samples in different acidic water environments. When the stress was $<1 \mathrm{MPa}$, the original fracture closed after loading. As the $\mathrm{pH}$ increased, the full stress-strain curves rose faster, and the fluctuations before the peak increased. When the $\mathrm{H}^{+}$concentration in the soaking solution was higher, the weakening effect on the coal samples was more evident. As a result, the uniaxial compressive strength and elastic modulus decreased, the peak strain increased, and the duration of the residual strength stage showed an increasing trend. The water caused the coal samples to soften and swell, while $\mathrm{H}^{+}$reacted with the mineral components of the coal samples. In summary, the combination of the above processes changed the strength, stiffness, morphology, and adhesion of the internal structure of the samples, resulting in changes in the macro-mechanical properties of the coal.

Table 4 shows the main mechanical parameters of the coal samples. The average strength of the coal samples soaked in solutions with pHs of 2,4 , and 6 was $4.5,6$, and $7.8 \mathrm{MPa}$, respectively, which is $60 \%, 80 \%$, and $104 \%$ of the $7.5 \mathrm{MPa}$ of the samples soaked in distilled water. Coal samples in Group A exhibited the most strength degradation, the most damage caused by physical and chemical interactions between water and minerals, and the least elastic modulus (388.8 MPa on 


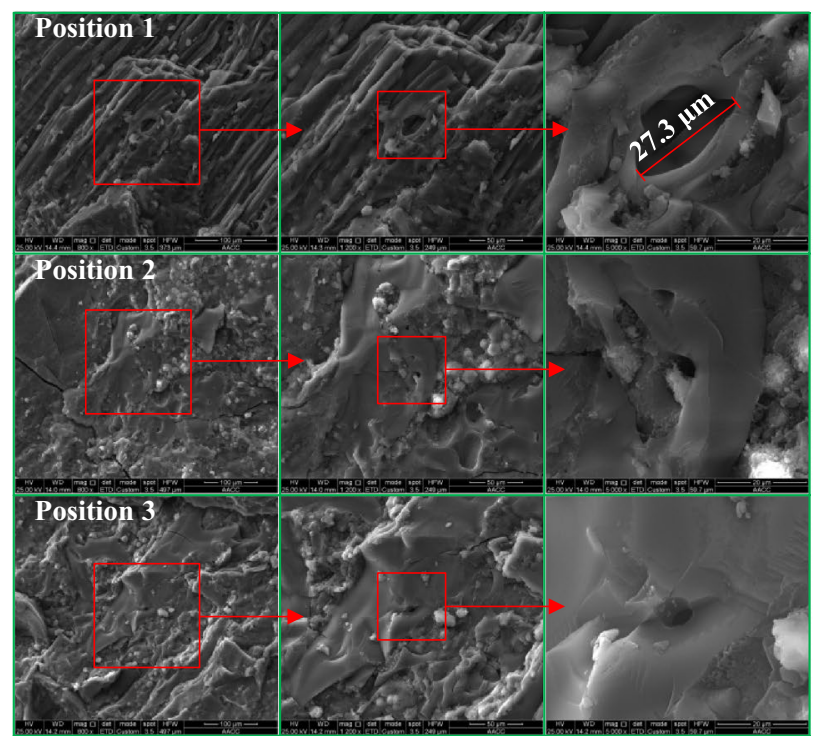

(a) Group A: $\mathrm{pH}=2$

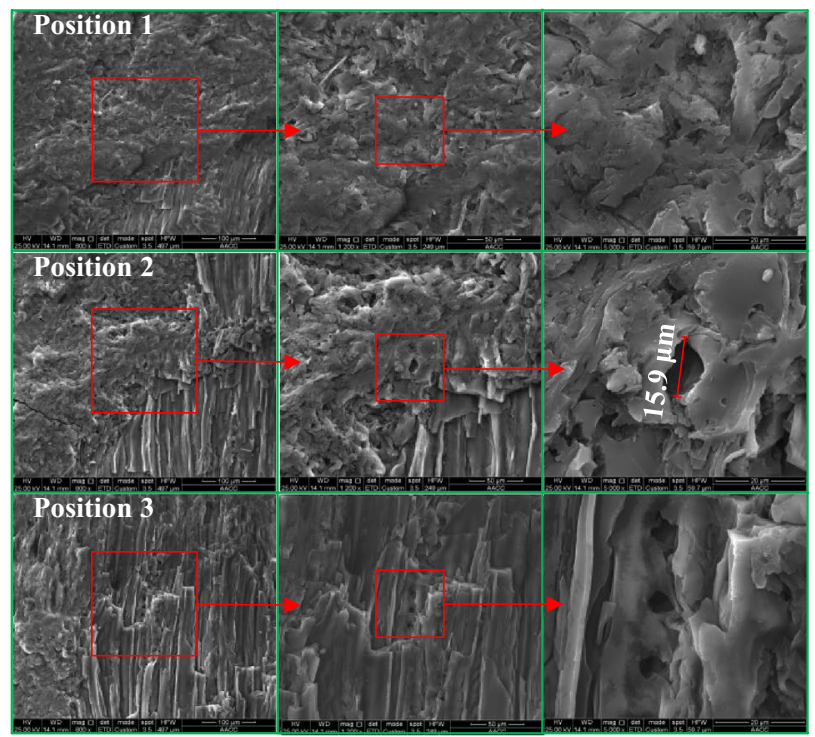

(c) Group $\mathrm{C}$ : $\mathrm{pH}=6$

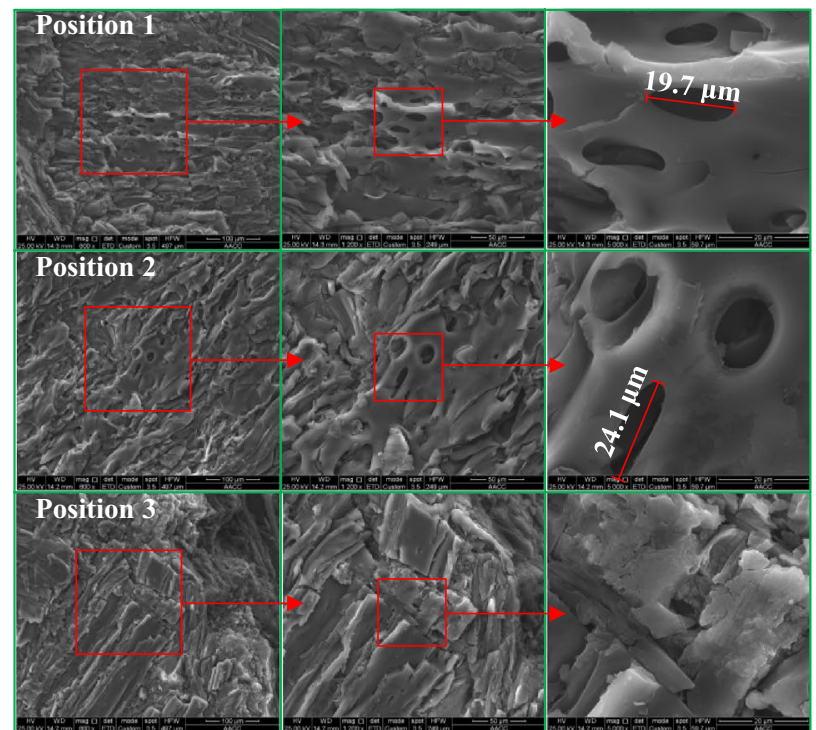

(b) Group B: $\mathrm{pH}=4$

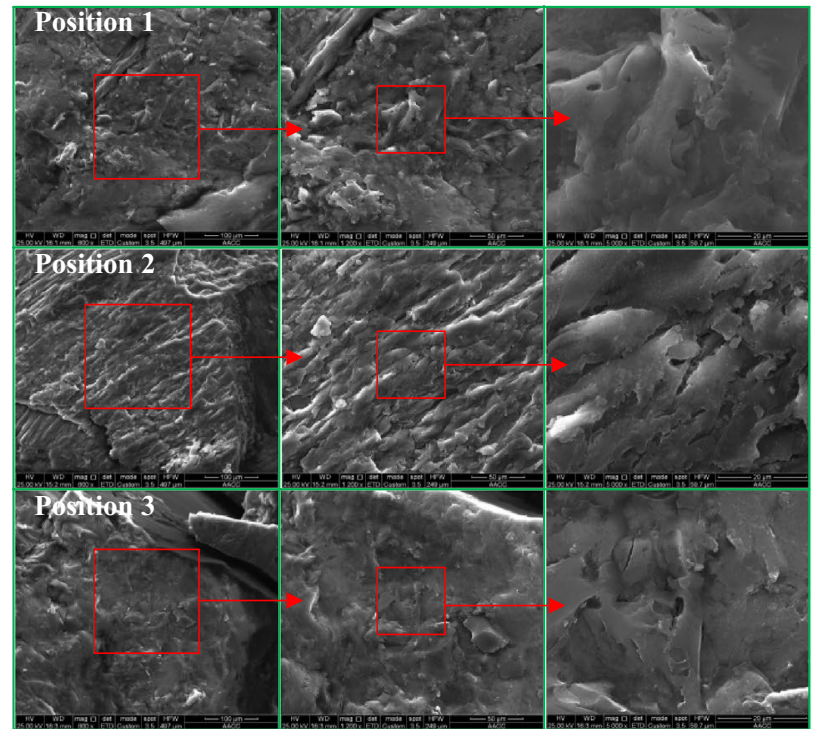

(d) Group D: $\mathrm{pH}=7.3$

Fig. 4 Microscopic structure and pore distribution of coal samples in different acidic environments

Table 2 Quantity of pores of different diameters in four sets of coal samples

\begin{tabular}{lllll}
\hline Pore size & $5-10 \mu \mathrm{m}$ & $10-15 \mu \mathrm{m}$ & $15-20 \mu \mathrm{m}$ & $20 \sim \mu \mathrm{m}$ \\
\hline Group A & 27 & 20 & 11 & 11 \\
Group B & 34 & 19 & 7 & 7 \\
Group C & 26 & 12 & 2 & 0 \\
Group D & 6 & 5 & 0 & 0 \\
\hline
\end{tabular}

Table 3 Mass percentages of the major element oxides (except carbon) in the coal samples

\begin{tabular}{lllll}
\hline $\mathrm{pH}$ & 2 & 4 & 6 & 7.3 \\
\hline $\mathrm{CaO}$ & 1.58 & 1.79 & 1.78 & 2.01 \\
$\mathrm{SrO}$ & 0.614 & 0.655 & 0.512 & 0.658 \\
$\mathrm{Al}_{2} \mathrm{O}_{3}$ & 0.132 & 0.19 & 0.44 & 0.633 \\
$\mathrm{Fe}_{2} \mathrm{O}_{3}$ & 0.443 & 0.445 & 0.839 & 0.408 \\
$\mathrm{SiO}_{2}$ & 0.535 & 0.79 & 0.833 & 1.24 \\
$\mathrm{SO}_{3}$ & 0.722 & 0.696 & 1.18 & 1.14 \\
$\mathrm{P}_{2} \mathrm{O}_{5}$ & 0.245 & 0.223 & 0.43 & 0.486 \\
\hline
\end{tabular}




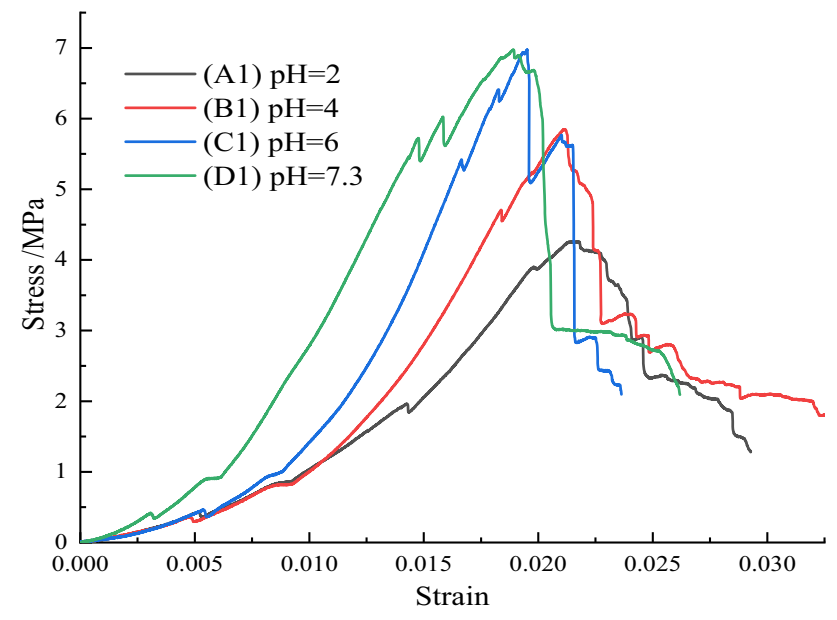

Fig. 5 Full stress-strain curves of coal samples in different acidic water environments

average). Samples soaked in a pH 6 solution and distilled water exhibited similar strengths, although the $\mathrm{H}^{+}$contained in these two groups of solutions differed by about an order of magnitude; the physical interaction between water and rock was the main factor influencing strength and deformation. As the $\mathrm{pH}$ of the solutions decreased, the average peak strain and plastic deformation capacity of the samples increased. The deformation capacity of the samples was restricted by sample strength; when the strength was small (e.g. Group A), the peak strain was reduced accordingly.

\section{Time-Domain Characteristics of Acoustic Emission}

In general, the loading process of the coal and rock mass is divided into a crack closure stage, an elastic stage, a stable crack growth stage, an unstable crack growth stage, and a post-peak stage. The instability failure of coal results from the generation, expansion, penetration, and structural deformation of fractures. The acoustic emission signals that are generated when fracturing or structural damage occurs have characteristic parameters (e.g. count, energy) that correspond well to different damage stages. Generally, a considerable quantity of acoustic emission events is observed during severe local or overall failure, which results in a rapid increase in the cumulative acoustic emission counts. In some cases, the ratio $r$ of accumulated counts per unit time to accumulated energy is used to evaluate the concentration of acoustic emission energy (Zhao et al. 2018). To allow a more intuitive interpretation, we used the average energy of acoustic emissions, namely $1 / r$, as the evaluation indicator. The crack development process, based on accumulated acoustic emission counts and average energy, are presented in Fig. 6.

In the crack closure and elastic stages, the samples underwent fracture closure and elastic deformation, resulting in slight damage and a small number of acoustic emission events. The stress curves and accumulated acoustic emission count curves both rose slowly; the average energy was $<1.5 \mathrm{~J}$ and the stress was transferred by elastic deformation. The stable crack growth stage was the beginning of evident damage to the samples, during which the stiffness increased, and the closed fractures started to move or mutually extend. The uneven stress on the crystals in the structure led to new fractures and the weak structural surface produced and accelerated the damage. At this stage, the slopes of the stress curves and accumulated acoustic emission count curves increased.

In the unstable crack growth stage, small fractures penetrated each other to form large fractures, the local structure showed fracture failures, and the overall damage increased sharply, resulting in a large number of acoustic emission events. The stress curves and accumulated acoustic emission count curves fluctuated upward. The maximum average
Table 4 The main mechanical parameters of the samples

\begin{tabular}{llllllll}
\hline No & $\mathrm{pH}$ & Peak stress/MPa & $\begin{array}{l}\text { Average peak } \\
\text { stress/MPa }\end{array}$ & $\begin{array}{l}\text { Elastic } \\
\text { modulus/ } \\
\text { MPa }\end{array}$ & $\begin{array}{l}\text { Average elastic } \\
\text { modulus/MPa }\end{array}$ & Peak strain & $\begin{array}{l}\text { Average } \\
\text { peak } \\
\text { strain }\end{array}$ \\
\hline $\mathrm{A} 1$ & 2 & 4.32 & 4.5 & 385.73 & 388.8 & 0.0177 & 0.020 \\
$\mathrm{~A} 2$ & & 4.88 & & 400.52 & & 0.0202 & \\
$\mathrm{~A} 3$ & & 4.26 & & 380.10 & & 0.0215 & \\
$\mathrm{~B} 1$ & 4 & 5.85 & 6 & 474.73 & 485.7 & 0.0211 & 0.021 \\
$\mathrm{~B} 2$ & & 6.46 & & 522.97 & & 0.0208 & \\
$\mathrm{~B} 3$ & & 5.61 & & 459.53 & & 0.0208 & \\
$\mathrm{C} 1$ & 6 & 8.15 & 7.8 & 678.68 & 699.8 & 0.0171 & 0.018 \\
$\mathrm{C} 2$ & & 6.98 & & 687.18 & & 0.0195 & \\
$\mathrm{C} 3$ & 8.19 & & 733.64 & & 0.0170 & \\
$\mathrm{D} 1$ & 7.3 & 6.99 & 7.5 & 686.23 & 667.9 & 0.0169 & 0.017 \\
$\mathrm{D} 2$ & 6.98 & & 633.07 & & 0.0189 & \\
$\mathrm{D} 3$ & 8.66 & & 684.42 & & 0.0144 & \\
\hline
\end{tabular}




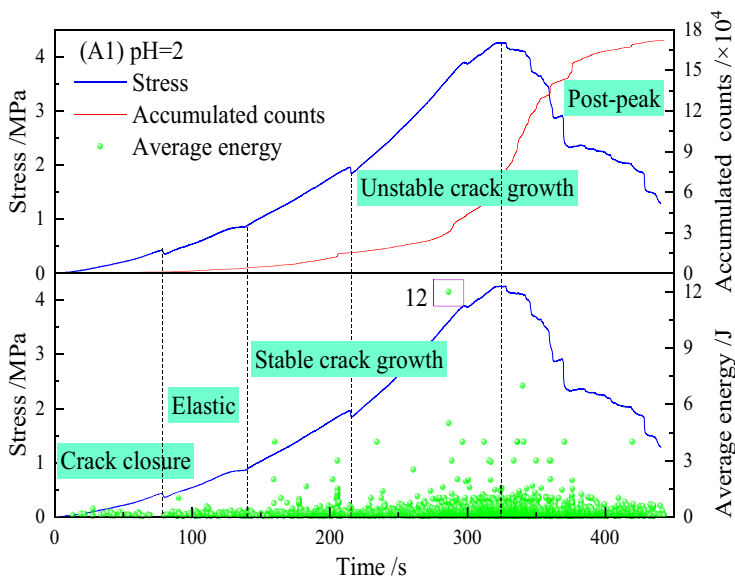

(a) Sample A1: $\mathrm{pH}=2$

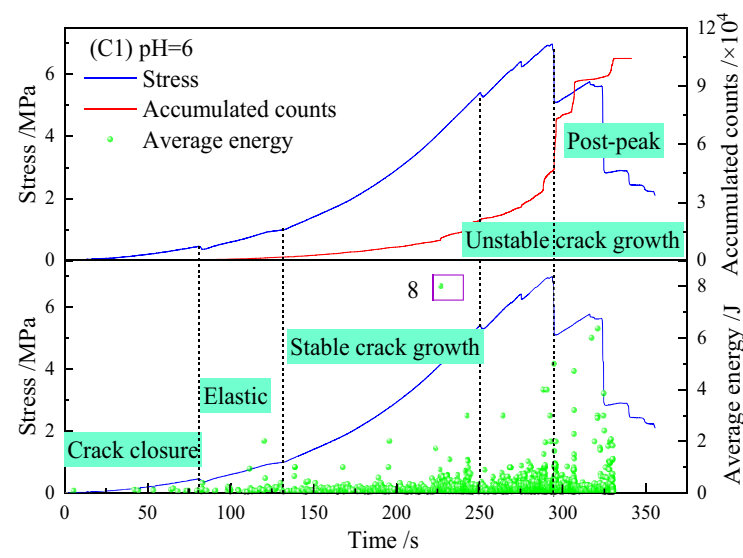

(c) Sample C1: $\mathrm{pH}=6$

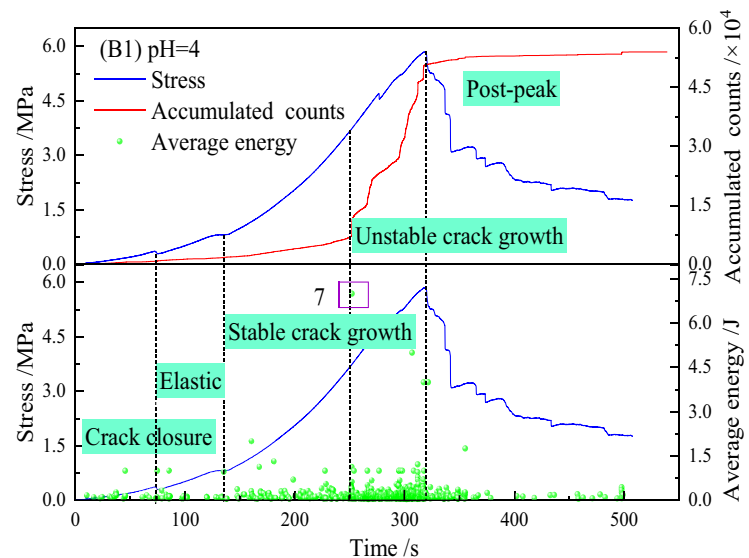

(b) Sample B1: $\mathrm{pH}=4$

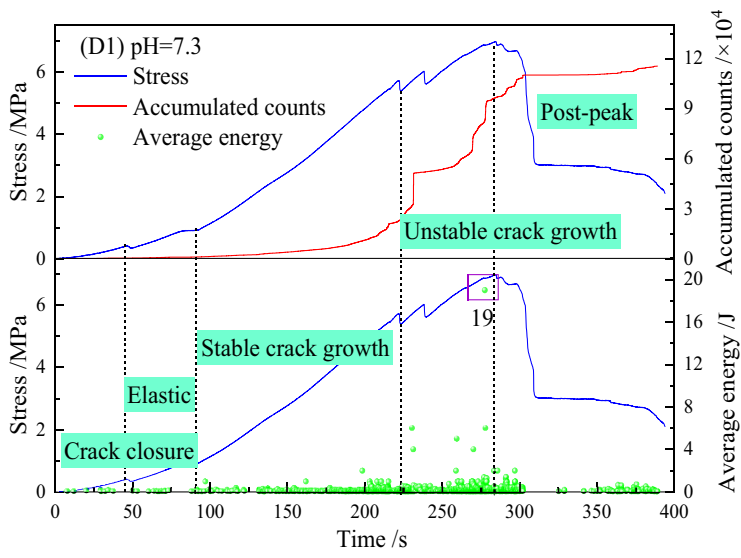

(d) Sample D1: $\mathrm{pH}=7.3$

Fig. 6 Stress vs. accumulated acoustic emission counts and average acoustic emission energy

energy of samples A1, B1, and D1 all appeared during the unstable crack growth stage, indicating that the most severe local damage occurred in these samples, generating highenergy acoustic emission signals. The maximum average energy of sample $\mathrm{C} 1$ appears in the stable crack growth stage, but only about $20 \mathrm{~s}$ before the unstable crack growth stage. At the peak stress site, the damage to the samples was relatively severe. Then, the stress curves dropped rapidly, the accumulated acoustic emission count curves rose sharply, and the average energy was at a high level. Notably, the average energy at the peak stress was not the maximum value during the loading process, which reflects that the failure of the main load-bearing structure was not an instantaneous behavior but rather a gradual process. The random local damage in the pre-peak stage aggravated the failure. In the residual stress stage, the load-bearing structure continued to experience fracturing or slip damage, and the average energy still remained at a high level.

At lower $\mathrm{pH}$, the stress curves and accumulated acoustic emission count curves near the peak stress and in the post-peak stage all changed from strongly fluctuating to smooth. The maximum average energy and cumulative acoustic emission counts at the peak stress stage first dropped and then climbed. At a solution $\mathrm{pH}$ of 4 , the minimum values of the maximum average energy and the accumulated acoustic emission count at the peak stress stage were $7 \mathrm{~J}$ and $5.8 \times 10^{4}$, respectively. The weakening effect of the acidic solution on the coal samples was due to the combined action of water and $\mathrm{H}^{+}$. $\mathrm{H}^{+}$promotes the dissolution of metal ions and salts in coal by water, which reduced the samples' structural rigidity and made them prone to plastic deformation. When the solution $\mathrm{pH}$ was 2 , clay minerals and other minerals dissolve from the coal, and the dissolution was faster than the softening rate. The brittle parts of the load-bearing structure of the samples caused local damage and failure, with higher energy released.

To further investigate fracture development and damage conditions during the failure process, the G-R relationship (Eq. 1) of seismology was applied to explore the 
time-domain characteristics of the acoustic emission events (Botvina and Tyutin 2019):

$\lg N(M)=a-b M$

where $\mathrm{M}$ represents the magnitude of the earthquake (Richter); $\mathrm{N}$ represents the earthquake frequency of the magnitude within the statistical interval; $a$ is a constant that represents the seismic activity level in the statistical area and the statistical time; and $b$ is a constant that represents the proportion of the number of large and small earthquakes (fracturing events). In calculating the acoustic emission $b$ values, $\mathrm{M}$ is usually represented by $1 / 20$ of the amplitude (Zhang and Zhang 2017). A high $b$ value shows that small fractures dominate, while a low $b$ value shows that large fractures are dominant; changes in $b$ indicate changes of fracture scale. Combined with the time of the uniaxial compression test, the time step was set at $50 \mathrm{~s}$, and the amplitude interval was set at $5 \mathrm{~dB}$ (Liu et al. 2019a). The variation of $b$ values with time is shown in Fig. 7.

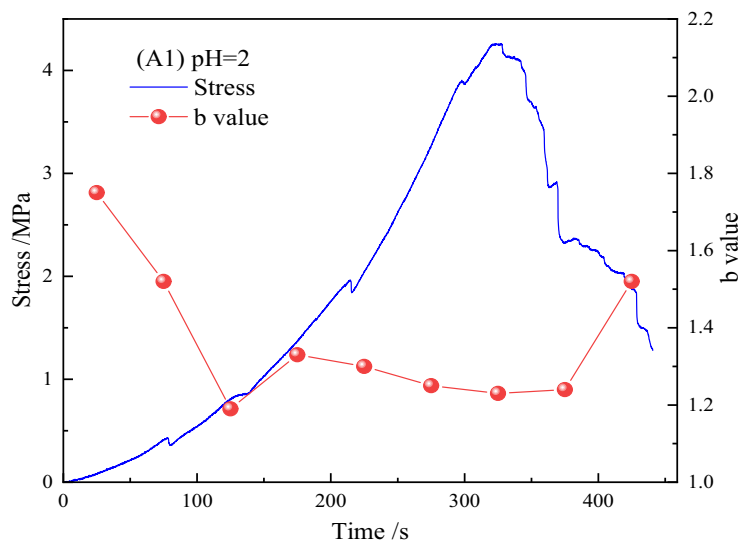

(a) Sample A1: $\mathrm{pH}=2$

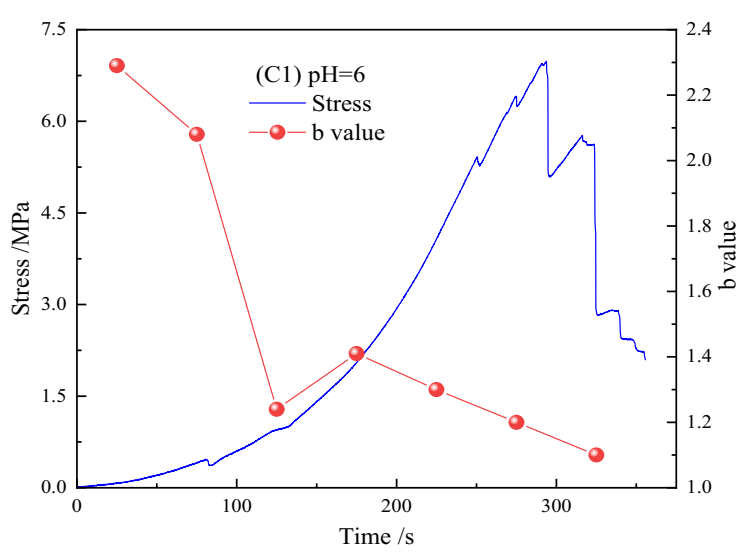

(c) Sample C1: $\mathrm{pH}=6$
At the beginning of loading, when the coal samples were only slightly damaged; the $b$ value was $>1.7$. As the stress increased, the change in the stress distribution caused the $b$ value to suddenly decrease, indicating that large changes had occurred inside the samples. Then, with more stress, there was a slight upward trend, and small fractures began to form. From the unstable crack growth stage, the $b$ value entered a continuous downward trend (except Fig. 7b) and small fractures continued to expand and connect, forming large fractures. The number of high-energy acoustic emission events increased, and the samples continued to be damaged until the stress dropped to the residual stress stage. The acoustic emission events were mainly in the range of 200-350 s, that is, in the unstable crack growth stage and a short time after the peak stress. There were relatively few acoustic emission events in the remaining statistical intervals.

The $b$ value of all samples showed a downward-upwarddownward trend before peak stress, which is in line with the process of fracture closure, elastic deformation, and fracture development. The initial $b$ value of the control group was

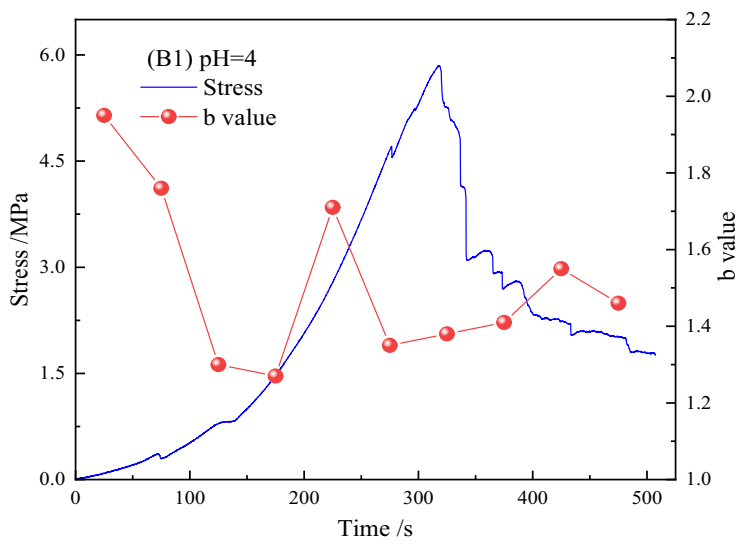

(b) Sample B1: $\mathrm{pH}=4$

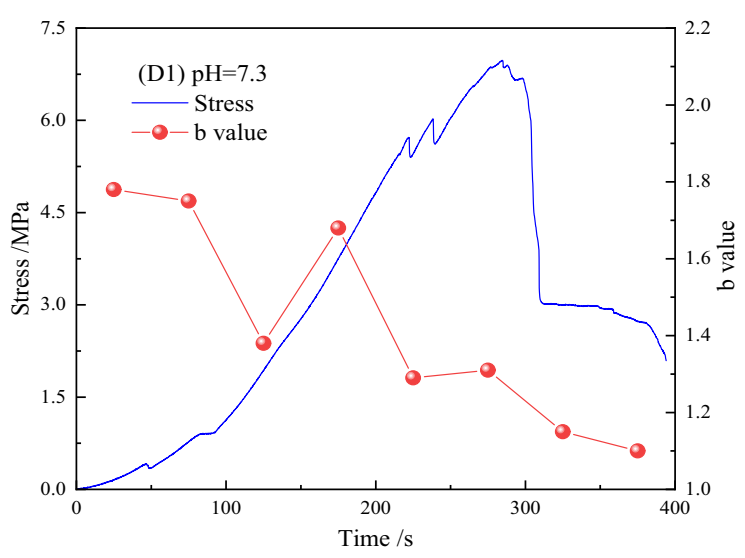

(d) Sample D1: $\mathrm{pH}=7.3$

Fig. 7 Variation of the $b$ value during the failure process of saturated samples with different $\mathrm{pH}$ values 
1.78. As the $\mathrm{pH}$ was decreased from 6 to 2 , the initial $b$ value gradually decreased. The $b$ value in groups $\mathrm{C}$ and $\mathrm{D}$ continued to decrease after the peak stress. The fact that the $\mathrm{H}^{+}$ concentration of these two groups was low and the difference was small shows that the water weakened the coal samples. After the peak stress of groups A and B, the $b$ value had an upward trend because $\mathrm{H}^{+}$promotes the expansion, dissolution, and migration of clay minerals. The internal structure of the samples gradually changed from the brittleness of mutual friction or stretching to the plasticity of extrusion deformation; relatively few large fractures were generated during the later stage.

\section{Statistical Analysis of Failure Modes}

\section{Correlation Between Acoustic Emission Frequency Spectrum and $\mathrm{pH}$}

The failure process and mechanism of coal and rock masses differ under various conditions and hence the frequency spectrum characteristics of acoustic emission signals are also different. This can help distinguish the damage state of engineering rock masses. Coal is a discontinuous medium and discontinuous failure occurs under loading, which generates intermittent pulse signals. For signals like this that present discrete forms in both the time and frequency domains, the acoustic emission time domain parameters can be converted to frequency domain parameters through the discrete Fourier transform (DFT) (Eq. 2) to obtain the relationship between acoustic emission amplitude and the corresponding frequency (Wang et al. 2020a).

$X(k)=\sum_{n=0}^{N^{\prime}-1} x(n) W_{N^{\prime}}^{k n}, \quad k=0,1, \ldots, N^{\prime}-1$

where $x(n)$ represents a finite-length sequence with a length of $\mathrm{M}^{\prime}$, and $\mathrm{N}^{\prime}$ represents the interval length ( $\left.\mathrm{N}^{\prime} \geq \mathrm{M}^{\prime}\right)$. In computer processing, this is generally simplified to the more efficient fast Fourier transform (FFT). Through frequency spectrum analysis, the frequency composition of acoustic emission signals was determined to differentiate acoustic emission signals more accurately at different stress or fracture development stages and to provide a reference for assessing the degree of damage.

Figure 8 shows the frequency spectrum characteristics of the coal samples. The acoustic emission amplitude was
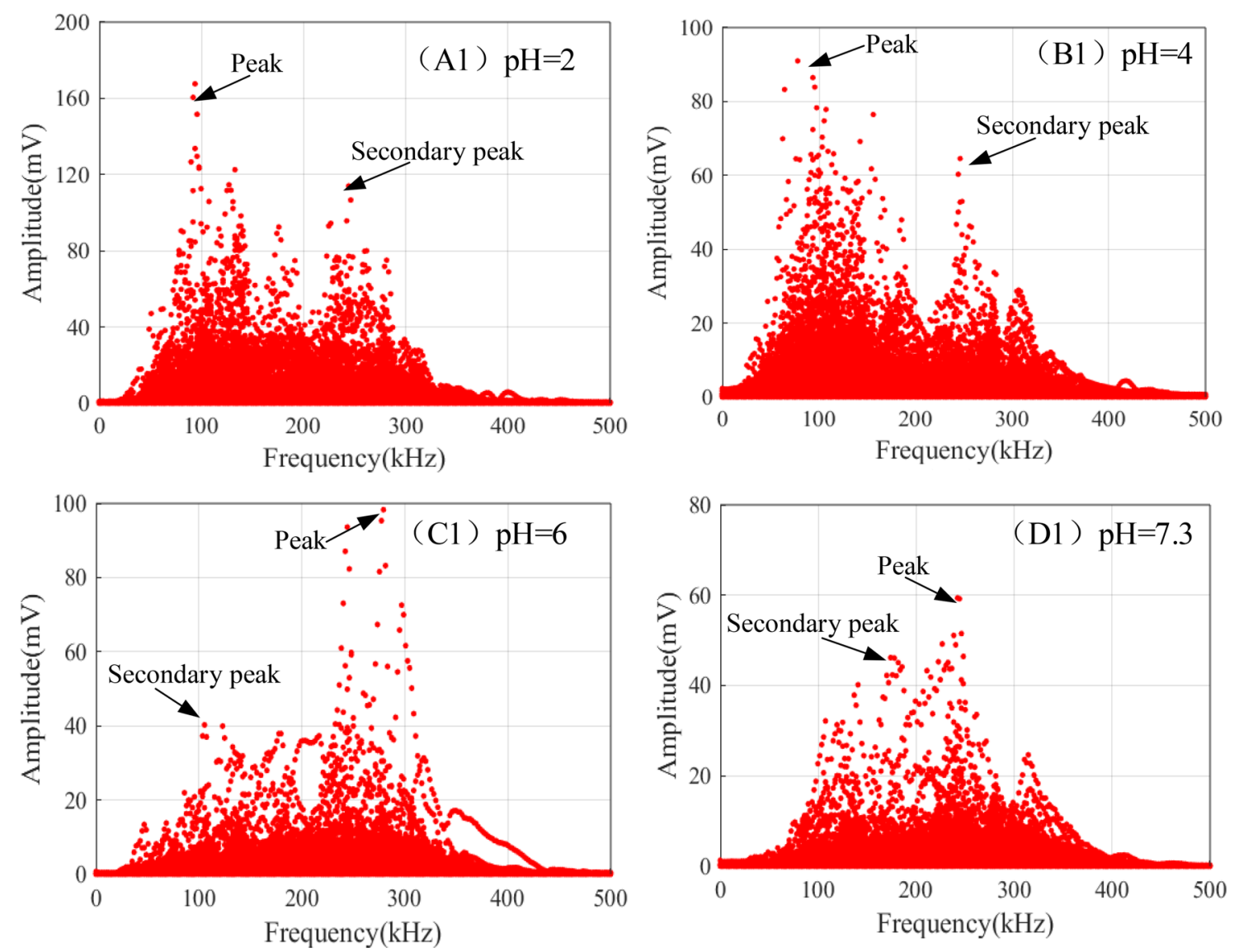

Fig. 8 Amplitude-frequency scatter plot 
unevenly distributed over the range of $0-1000 \mathrm{kHz}$, and the amplitude in the low-frequency range was greater than in the high-frequency range. When the frequency exceeded $500 \mathrm{kHz}$, the amplitude was $<2 \mathrm{mv}$ with no obvious characteristics; hence, frequencies above $500 \mathrm{kHz}$ are not shown. A large amplitude means that the energy of the acoustic emission signals was high, and the sample was heavily damaged. As can be seen from Fig. 8 and Table 5, amplitudes $>10$ mv mostly occurred in the range of $50-350 \mathrm{kHz}$, demonstrating characteristic double peaks, and were affected by the $\mathrm{pH}$ of the solutions. When the $\mathrm{pH}$ was 2 , the maximum amplitude was 170 $\mathrm{mv}$, the corresponding main frequency was $95 \mathrm{kHz}$, the secondary peak amplitude and secondary frequency were $115 \mathrm{mv}$ and $250 \mathrm{kHz}$, respectively, and the amplitude was mostly $<40$ $\mathrm{mv}$. When the $\mathrm{pH}$ was 4 , there were similar distribution characteristics; however, the maximum amplitude and secondary peak amplitude were only 90 and $65 \mathrm{mv}$, respectively, and most of the amplitudes were $<20 \mathrm{mv}$. Samples C1 and D1 were neutral, and the positions of the two peaks were opposite to those of the first two groups. The secondary peak amplitude was at the lower frequency position, while the maximum amplitude was at the higher frequency position. According to previous studies Kong et al. (2017), Yang et al. (2019a), high-frequency acoustic emission events intensively occur in the unstable crack growth stage before peak stress. The effect of $\mathrm{H}^{+}$on the acoustic emission frequency spectrum is mainly manifested as a shift in the position of the main frequency to a lower frequency. High-frequency signals are related to fracture initiation, while low-frequency signals are related to the formation of large fractures. The results suggest that during the failure of low-pH samples (groups A and B), the acidic solutions reduce the structural strength of the coal samples through physical and chemical interactions, and the coal samples show relatively fewer small fractures under loading and can easily form large fractures directly through the weakened zone. In contrast, the near-neutral samples (groups C and D) are mainly at high frequency and show brittle fracture characteristics. Under loading, a lot of small fractures are generated and then connect with and penetrate each other, finally forming large fractures.

\section{Correlation Between Fracture Mode and pH}

Acoustic emissions induced by tensile fractures exhibit high frequency and short rise time, while acoustic emissions induced by shear fractures exhibit low frequency

Table 5 Main frequency and secondary frequency

\begin{tabular}{lllll}
\hline $\mathrm{pH}$ value & 2 & 4 & 6 & 7.3 \\
\hline Main frequency/kHz & 95 & 80 & 280 & 250 \\
Secondary frequency $/ \mathrm{kHz}$ & 250 & 250 & 105 & 180 \\
\hline
\end{tabular}

and long rise time (Yao et al. 2019). Hence, the RA (rise angle) - AF (average frequency) relation can be used to distinguish the failure modes of coal: high RA with low $\mathrm{AF}$ is shear fracture, while low RA with high AF is tensile fracture, where RA refers to the ratio of the rise time to the amplitude, and AF refers to the ratio of the ringing count to the duration.

Figure 9 shows the RA-AF relation cloud diagrams and the failure modes of saturated samples soaked in solutions with different $\mathrm{pH}$ values. The red area in the cloud diagram represents the maximum data density and the blue area represents the minimum data density $(0$, no data). The data in the RA range of $0-1000 \mathrm{~ms} / \mathrm{v}$ and the AF range of $0-500 \mathrm{kHz}$ account for more than $95 \%$ of the total data, which is typical. The small number of discrete values in the RA range of 501-1000 ms/v and the AF range of $1001-3500 \mathrm{kHz}$ were not analyzed. The data are concentrated near the vertical axis and have the characteristics of low RA and high AF, representing a large number of tensile fractures. Some data are distributed near the horizontal axis, which represent shear fractures. By considering both the density cloud maps and the failure mode maps, it can be seen that tensile fractures are the main factor behind the failure and instability of samples. Since all four groups were saturated samples, their fracture morphology is similar. Sample A1 has the largest red tensile fracture area: there are numerous parallel tensile fractures and a number of shear fractures are also present inside. However, these shear fractures do not appear on the surface of the sample. Sample B1 has fewer tensile fractures and shear fractures than sample A1. The failed samples mainly contain penetrated tensile fractures, with large pieces of the coal having fallen off. Sample $\mathrm{C} 1$ is dominated by composite tensile and shear fractures; numerous small fractures have connected, forming a weak surface, so that one side of the surface fell off. The shear fractures in Sample D1 are the most evident, showing a local $\mathrm{x}$-shaped failure.

Coal-measure sedimentary rocks show apparent bedding characteristics. This natural weak structural surface has a significant effect on the strength and failure modes. The cement on the bedding surface is relatively chemically active. Tensile failure in the acidic water environments directly caused the sample failure. Under the long-term action of water, the adhesion and friction of the coal samples were reduced, creating favorable conditions for shear failure, such as in sample D1. The $\mathrm{H}^{+}$in the water chemically reacted with the coal minerals, separating them from the original structure of the coal samples. Consequently, the microstructural form changed (Fig. 4) and the structural strength was reduced (Fig. 5). Damage to the bedding surfaces and other weak surfaces is especially evident. When the $\mathrm{H}^{+}$concentration was higher, the chemical reactions were stronger and it was easier for the weak surfaces of the 

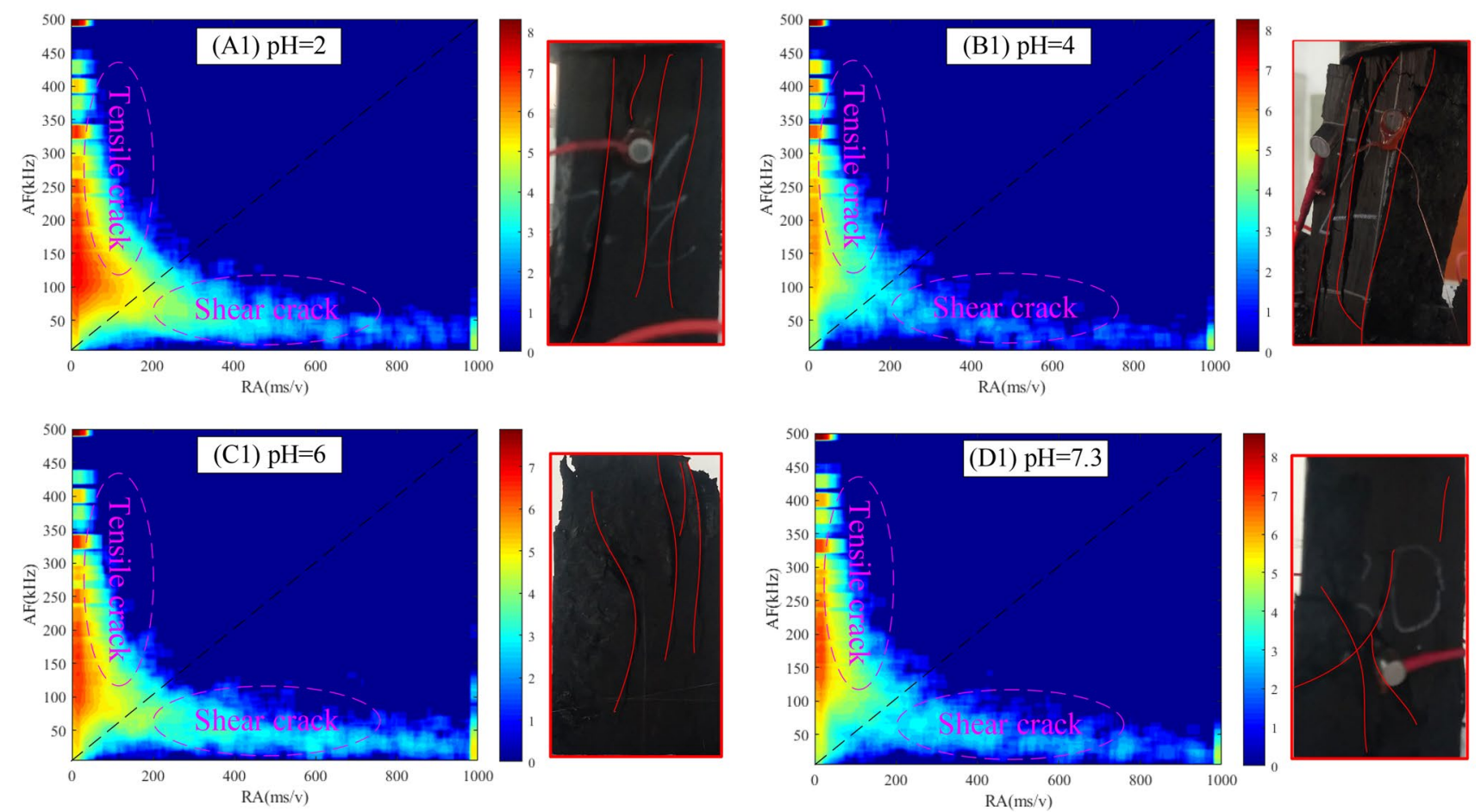

Fig. 9 Relationship between RA-AF and sample failure mode

samples to connect, causing separation of large blocks and instability failure.

\section{Discussion}

\section{Chemical Reaction of Coal with Acid Aqueous Solutions}

According to Table 3, the average $\mathrm{CaO}$ content was $1.8 \%$. Combined with another XRD test result (not shown in this work), the calcite content was relatively high among the minerals contained in coal, which indicates that the coal easily reacts with $\mathrm{H}^{+}$in the solution.

Kaolinite, which has a layered structure, swells when exposed to water and easily reacts with acid (Eq. 3). This is the main factor influencing the water content and plastic deformation of the coal. The Si content is higher than that of $\mathrm{Al}$, indicating that not all of the $\mathrm{Si}$ comes from kaolinite and part of the $\mathrm{Si}$ comes from potash feldspar $\left(\mathrm{K}_{2} \mathrm{O} \cdot \mathrm{Al}_{2} \mathrm{O}_{3} \cdot 6 \mathrm{SiO}_{2}\right)$.

$$
\mathrm{Al}_{2} \mathrm{Si}_{2} \mathrm{O}_{5}(\mathrm{OH})_{4}+6 \mathrm{H}^{+}=2 \mathrm{Al}^{3+}+2 \mathrm{H}_{2} \mathrm{SiO}_{3}+3 \mathrm{H}_{2} \mathrm{O}
$$

In neutral water environments, $\mathrm{Fe}$ and $\mathrm{S}$ exist as minerals with bound water (e.g. $\mathrm{Fe}_{2} \mathrm{O}_{3} \cdot \mathrm{nH}_{2} \mathrm{O}, \mathrm{CaSO}_{4} \cdot 2 \mathrm{H}_{2} \mathrm{O}$ ); meanwhile, in acidic solutions, they exist as $\mathrm{Fe}^{2+}, \mathrm{Fe}^{3+}$, and
$\mathrm{SO}_{4}{ }^{2-}$. In neutral water environments, the surfaces of minerals are attached to a water film or bound water. This leads increases the inter-particle distance and weakens the cohesive force. As the solution $\mathrm{pH}$ decreases, the minerals in the coal dissolve, weakening the cementation and increasing the porosity (consistent with the SEM results in Fig. 4). Since this work only studied the influence of $\mathrm{H}^{+}$in solutions, the competing effects of ions that may exist in actual mine water, such as $\mathrm{Ca}^{2+}, \mathrm{Mg}^{2+}$, and $\mathrm{HCO}^{3-}$, will not be discussed. Under the action of geochemistry and microbial catalysis, the redox environment of coal fields (including abandoned mines) changes, and the produced acid mine water is conducive to the transfer of metal ions to wider areas and water pollution (Galhardi and Bonotto 2016; Li et al. 2018).

\section{Data Error Analysis}

Although various measures were taken to ensure that the samples has the same initial characteristics, coal is inherently anisotropic and uncertain. In the case of Group A, the dry coal sample ultrasonic velocities were different, with an average ultrasonic velocity of 1.52 , a standard deviation of 0.063 , and a coefficient of variation of 0.041 (Fig. 3). After the coal samples were immersed in acidic solutions, the ultrasonic velocity was 1.49 on average, with a standard deviation of 0.158 and a coefficient of variation of 0.106 . If the ultrasonic velocity is used as a standard to measure the 
coal sample difference (or discreteness), the decreased average ultrasonic velocity and increased standard deviation and coefficient of variation indicate that the sample difference after immersion increases (water and hydrogen ions change the coal sample structure and composition). Similar trends occurred in Groups B and C. Actually, the coefficient of variation of the four groups of dry coal samples is $0.041,0.074$, 0.08 , and 0.032 , respectively, which may have influenced subsequent experimental results. Table 4 shows that the mechanical parameters are obviously related to the solution acidity. Taking the peak stress of Group A as an example, the average peak stress, standard deviation, and coefficient of variation were $4.5,0.28$, and 0.062 , respectively, among which the coefficient of variation was between that of dry and saturated coal samples. However, for Groups B and C, the coefficient of variation was less than for dry and saturated coal samples, but for Group D, the value was larger. This indicates that compared with the samples' physical characteristics, represented by their ultrasonic velocity, the deviation degree of uniaxial compressive strength (as well as elastic modulus) of coal samples in acidic water environments decreases.

\section{Conclusions}

The stability of coal pillar dams is affected by acidic water environments. In this study, the effects of $\mathrm{H}^{+}$in acidic solutions on the structure, composition, and mechanical and acoustic characteristics of coal samples were investigated by a series of physical and mechanical tests. The following conclusions can be drawn:

(1) The softening and dissolution of associated minerals and the chemical action of $\mathrm{H}^{+}$damaged the coal samples. The overall ultrasonic velocity showed a downward trend, dropping by $0.031-0.218 \mathrm{~km} / \mathrm{s}$. At lower $\mathrm{pH}$ values, the pore sizes on the coal sample microstructure surfaces were larger and the number of large pores increased. When the $\mathrm{pH}$ was less than 4 , pores with a diameter $>20 \mu \mathrm{m}$ appeared.

(2) As the $\mathrm{H}^{+}$concentration increased, the average uniaxial compressive strength decreased from 7.8 to $4.5 \mathrm{MPa}$, the average elastic modulus decreased from 699.8 to $388.8 \mathrm{MPa}$, except for control group D (7.5 MPa and 667.9 MPa, respectively), while the duration of the residual strength stage increased. Significant increases in both the accumulated acoustic emission counts and the maximum average energy occurred near the unstable crack growth stage. With progressive loading, the $b$ value presents a downward-upwarddownward trend before the peak stress of all samples and continued to decrease after the peak under high $\mathrm{pH}$ values and to increase in a fluctuating manner under low $\mathrm{pH}$ values.

(3) The maximum amplitude of coal samples with $\mathrm{pH}$ values of 2 and 4 was observed at $\approx 100 \mathrm{kHz}$, while the maximum amplitude of samples with $\mathrm{pH}$ values of 6 and 7.3 was observed at $\approx 250 \mathrm{kHz}$. The former indicates that the failure was probably due to large damaged areas, while the latter indicates that the failure mode was due to the connection of small fractures. $\mathrm{H}^{+}$promotes tensile failure of the weak structures of coal samples.

Acknowledgements This work was supported by the National Natural Science Foundation of China (Grants 51674248 and 51874283).

Open Access This article is licensed under a Creative Commons Attribution 4.0 International License, which permits use, sharing, adaptation, distribution and reproduction in any medium or format, as long as you give appropriate credit to the original author(s) and the source, provide a link to the Creative Commons licence, and indicate if changes were made. The images or other third party material in this article are included in the article's Creative Commons licence, unless indicated otherwise in a credit line to the material. If material is not included in the article's Creative Commons licence and your intended use is not permitted by statutory regulation or exceeds the permitted use, you will need to obtain permission directly from the copyright holder. To view a copy of this licence, visit http://creativecommons.org/licenses/by/4.0/.

\section{References}

Botvina LR, Tyutin MR (2019) New acoustic parameter characterizing loading history effects. Eng Fract Mech 210(SI):358-366

Cai X, Zhou ZL, Liu KW, Du XM, Zang HZ (2019) Water-weakening effects on the mechanical behavior of different rock types: phenomena and mechanisms. Appl Sci 9(20):4450

Chang QL, Chen JH, Zhou HQ, Bai JB (2014) Implementation of paste backfill mining technology in Chinese coal mines. Sci World J 2014:821025

Corteel C, Dini A, Deyhle A (2005) Element and isotope mobility during water-rock interaction processes. Phys Chem Earth 30(17-18):993-996

Ding K (1989) Geochemical dynamics of water rock interaction. Geol Geochem 1989(6):29-38 (in Chinese)

Fan LM, Ma XD, Jiang ZQ, Sun K, Ji RJ (2019) A 30-year review and prospect of water retaining coal mining research. Coal Sci Technol 47(7): 1-30 (in Chinese)

Feng WL, Qiao CS, Niu SJ, Yu MY, Jia ZQ (2019) Macro-mechanical properties of saturated sandstone of Jushan Mine under post-peak cyclic loading: an experimental study. Arab J Geosci 12(23):702

Galhardi JA, Bonotto DM (2016) Hydrogeochemical features of surface water and groundwater contaminated with acid mine drainage (AMD) in coal mining areas: a case study in southern Brazil. Environ Sci Pollut Res 23(18):18911-18927

Gu DZ (2015) Theory framework and technological system of coal mine groundwater reservoir. J China Coal Soc 40(2):239-246 (in Chinese)

Gu HL, Tao M, Cao WZ, Zhou J, Li XB (2019) Dynamic fracture behaviour and evolution mechanism of soft coal with different porosities and water contents. Theor Appl Fract Mech 103:102265

Guo J, Feng GR, Qi TY, Wang PF, Yang J, Li Z, Bai JW, Du XJ, Wang ZH (2018) Dynamic mechanical behavior of dry and water saturated igneous rock with acoustic emission monitoring. Shock Vib 2018:2348394

Hao RQ, Li JT, Cao P, Liu B, Liao J (2015) Test of subcritical crack growth and fracture toughness under water-rock interaction in three types of rocks. J Cent South Univ 22(2):662-668 
Huang QX (2017) Research on roof control of water conservation mining in shallow seam. J China Coal Soc 42(1):50-55 ((in Chinese))

Kong B, Wang EY, Li ZH, Wang XR, Niu Y, Kong XG (2017) Acoustic emission signals frequency-amplitude characteristics of sandstone after thermal treated under uniaxial compression. J Appl Geophys 136:190-197

Li GR, Lei YL, Ge JP, Wu SM (2017) The empirical relationship between mining industry development and environmental pollution in China. Int J Env Res Pub He 14(3):254

Li QG, Wu P, Zha XF, Li XX, Wu LN, Gu SY (2018) Effects of mining activities on evolution of water chemistry in coal-bearing aquifers in karst region of midwestern Guizhou, China: evidences from $\delta^{13} \mathrm{C}$ of dissolved inorganic carbon and $\delta^{34} \mathrm{~S}$ of sulfate. Environ Sci Pollut Res 25(18):18038-18048

Li BY, Liu J, Bian K, Ai F, Hu XJ, Chen M, Liu ZP (2019) Experimental study on the mechanical properties weakening mechanism of siltstone with different water content. Arab J Geosci 12(21):656

Lin Y, Zhou KP, Gao F, Li JL (2019) Damage evolution behavior and constitutive model of sandstone subjected to chemical corrosion. B Eng Geol Environ 78(8):5991-6002

Liu XL, Liu Z, Li XB, Han MS (2019a) Study on b-value characteristics of acoustic emission of limestone under uniaxial compression and splitting load. Rock Soil Mech 40(S1):267-274 (in Chinese)

Liu Y, Yuan SC, Yang BB, Liu JW, Ye ZY (2019b) Predicting the height of the water-conducting fractured zone using multiple regression analysis and GIS. Environ Earth Sci 78(14):422

Ma CQ, Li HZ, Niu Y (2018) Experimental study on damage failure mechanical characteristics and crack evolution of water-bearing surrounding rock. Environ Earth Sci 77(1):23

Ma DH, Yao HY, Cui Q, Cheng SL (2019) Influence of aqueous solution on mechanical properties of limestone. China Sci 14(8):846851 ((in Chinese))

Madzivire G, Maleka PP, Vadapalli VRK, Gitari WM, Lindsay R, Petrik LF (2014) Fate of the naturally occurring radioactive materials during treatment of acid mine drainage with coal fly ash and aluminium hydroxide. J Environ Manag 133:12-17

Miao XX, Cui XM, Wang JA, Xu JL (2011) The height of fractured water-conducting zone in undermined rock strata. Eng Geol 120(1-4):32-39

Qian RP, Feng GR, Guo J, Wang PF, Jiang HN (2019) Effects of watersoaking height on the deformation and failure of coal in uniaxial compression. Appl Sci 9(20):4370

Song HQ, Xu JJ, Fang J, Cao ZG, Yang LZ, Li TX (2020) Potential for mine water disposal in coal seam goaf: Investigation of storage coefficients in the Shendong mining area. J Clean Prod 244:118646

Sun WB, Wang Y, Qiu HF, Ding ZW (2020) Numerical simulation study of strip filling for water-preserved coal mining. Environ Sci Pollut Res 27(12):12899-12907

Tang CJ, Yao QL, Li ZY, Zhang Y, Ju MH (2019) Experimental study of shear failure and crack propagation in water-bearing coal samples. Energy Sci Eng 7(5):2193-2204
Wang W, Qiang YX, Wang Y, Sun QM, Zhang M (2016) Impacts of Yuyang coal mine on groundwater quality in Hongshixia water source, northwest China: a physicochemical and modeling research. Expos Health 8(3):431-442

Wang BY, Qin Y, Shen J, Wang G, Zhang QS, Liu M (2019a) Experimental study on water sensitivity and salt sensitivity of lignite reservoir under different $\mathrm{pH}$. J Pet Sci Eng 172:1202-1214

Wang F, Cao P, Cao RH, Xiong XG, Hao J (2019b) The influence of temperature and time on water-rock interactions based on the morphology of rock joint surfaces. B Eng Geol Environ 78(5):3385-3394

Wang FT, Liang NN, Li G (2019c) Damage and failure evolution mechanism for coal pillar dams affected by water soaking in groundwater reservoirs. Geofluids 2019:2985691

Wang CY, Chang XK, Liu YL, Guo WB (2020a) Experimental study on acoustic emission spectrum evolution characteristics of marble fracture process under uniaxial compression. Rock Soil Mech 41(S1):51-62

Wang YP, Liu XJ, Liang LX, Xiong J (2020b) Experimental study on the damage of organic-rich shale during water-shale interaction. J Nat Gas Sci Eng 74:103103

Yang YJ, Ma DP, Zhou Y (2019a) Experimental study on acoustic emission intrinsic frequency spectrum characteristics of coal and rock under triaxial unloading confining pressure. J Min Safe Eng 36(5):1002-1008 (in Chinese)

Yang Z, Li WP, Li XQ, He JH (2019b) Quantitative analysis of the relationship between vegetation and groundwater buried depth: a case study of a coal mine district in western China. Ecol Indicat 102:770-782

Yao QL, Chen T, Tang CJ, Sedighi M, Wang SW, Huang QX (2019) Influence of moisture on crack propagation in coal and its failure modes. Eng Geol 258:105156

Yu Z, Zhang L, Jiang P, Papelis C (2015) Study on water-rock interactions of trace elements in groundwater with leaching experiments. Groundwater 53(S1):95-102

Zhang Q, Zhang XP (2017) A numerical study on cracking processes in limestone by the $\mathrm{b}$-value analysis of acoustic emissions. Comput Geotech 92:1-10

Zhao K, Zhou YT, Zeng P, Lu CY (2018) Experimental study on acoustic emission characteristics of rock-like materials with different particle sizes under three-point bending. J China Coal Soc 43(11):3107-3114 ((in Chinese))

Zhou JR, Wei J, Yang TH, Zhu WC, Li LC, Zhang PH (2018) Damage analysis of rock mass coupling joints, water and microseismicity. Tunn Undergr Sp Tech 71:366-381

Zhu WB, Yu SC, Xuan DY, Shan ZJ, Xu JL (2018) Experimental study on excavating strip coal pillars using caving zone backfill technology. Arab J Geosci 11(18):554 